\title{
BMJ Open Quality of care, resource use and patient outcome by use of emergency response team compared with standard care for critically ill medical patients in the emergency department: a retrospective single-centre cohort study from Norway
}

Stine Engebretsen (1) , , ${ }^{1,2}$ Stig Tore Bogstrand, ${ }^{3,4}$ Dag Jacobsen, ${ }^{2,5}$ Rune Rimstad ${ }^{6,7}$

To cite: Engebretsen $\mathrm{S}$, Bogstrand ST, Jacobsen D, et al. Quality of care, resource use and patient outcome by use of emergency response team compared with standard care for critically ill medical patients in the emergency department: a retrospective single-centre cohort study from Norway. BMJ Open 2021;11:e047264. doi:10.1136/ bmjopen-2020-047264

- Prepublication history and additional supplemental material for this paper are available online. To view these files, please visit the journal online. (http://dx.doi.org/10.1136/ bmjopen-2020-047264)

Received 23 November 2020 Accepted 30 July 2021

Check for updates

(c) Author(s) (or their employer(s)) 2021. Re-use permitted under CC BY-NC. No commercial re-use. See rights and permissions. Published by BMJ.

For numbered affiliations see end of article.

Correspondence to

Stine Engebretsen;

stenge@ous-hf.no

\section{ABSTRACT}

Objective The study aimed to investigate quality of care, resource use and patient outcome in management by an emergency response team versus standard care for critically ill medical patients in the emergency department (ED). The emergency response team was multidisciplinary and had eight members, with a registrar in internal medicine as team leader.

Design Register-based retrospective cohort study. Setting Tertiary hospital in Norway.

Participants The study included 1120 patients with National Early Warning Score 2 (NEWS2) 5-10 points from 2015 and 2016. Patients missing $\geq 3$ NEWS2 part scores, $<18$ years and with orders 'Not for ICU' or 'Not for resuscitation' were excluded.

Outcome measures Quality of care: pain assessment documented, analgesics given within $20 \mathrm{~min}$, complete set of vital signs documented and antibiotics within 60 min if sepsis. Resource use: $>3$ diagnostic interventions, critical care in the ED and ED length of stay (LOS) <180 min. Patient outcome: intensive care unit (ICU) admission, ICU LOS <66 hours, hospital LOS $<194$ hours and mortality.

Results The median age was 66 years, $53.5 \%$ were male, $44.3 \%$ were admitted to the ICU and the mortality rate was $10.6 \%$. Altogether 691 patients received team management and 429 standard care. Team management had a positive association with 'complete set of vital signs documented' (OR 1.720, Cl 1.254 to 2.360), 'analgesics given within 20 minutes' (OR 3.268, $\mathrm{Cl} 1.375$ to 7.767 ) and 'antibiotics within 60 minutes if sepsis' (OR 7.880, Cl 3.322 to 18.691), but a negative association with ' pain assessment documented' (OR 0.068, $\mathrm{Cl} 0.037$ to 0.128 ). Team management was also associated with 'critical care in the ED' (OR 9.900, Cl 7.127 to 13.751), 'ED LOS $<180$ min' (OR 2.944, Cl 2.070 to 4.187), 'ICU admission' (OR 2.763, Cl 1.962 to 3.891) and 'mortality' (OR 1.882, Cl 1.142 to 3.102 ).

Conclusions Team management showed positive results for quality of care and resource use. The results for later outcomes such as mortality, ICU LOS and hospital LOS were more ambiguous.
Strengths and limitations of this study

- The use of register data made it possible to include a large group of patients.

- Multivariate analyses allowed adjustment for several factors that could influence on the outcomes.

- The observational nature of the study makes it difficult to draw conclusions about the cause and effect of the two types of management under investigation.

- The registers did not include data on all cofactors relevant for late outcomes.

- The single-centre design could limit representativeness.

\section{INTRODUCTION}

The use of multidisciplinary emergency response teams has become more widespread over the last years, in a variety of settings and for different patient groups, and also in the emergency department (ED). Trauma teams and cardiac arrest teams have existed for several decades. ${ }^{12}$ Teams for specific conditions such as myocardial infarction and stroke have become more common, ${ }^{34}$ as have the use of medical emergency teams or critical care outreach for deteriorating ward patients. ${ }^{25}$

Management by emergency response teams has promising effects on time to treatment, mortality and morbidity in specific conditions such as trauma, stroke, sepsis and ST-elevation myocardial infarction. ${ }^{6-10}$ The effect on more undifferentiated conditions such as in deteriorating ward patients is more unclear. ${ }^{11}$ The use of team could divert resources away from other patients and be time-consuming and expensive, ${ }^{11}$ and it is therefore important to correctly identify which patients benefit from it. 
It is well known that critically ill patients in need of intensive care unit (ICU) admission could receive suboptimal care in the ED and that prolonged ED length of stay (LOS) may cause sentinel events and even increase mortality. ${ }^{12-14}$ Despite this and the knowledge about the positive effect of emergency response teams for other patient groups, only a few studies have investigated the use of emergency response teams for critically ill general medical patients in the ED. These studies found that although many EDs do not use such teams, team management could ensure early diagnosis and treatment and a shorter ED LOS. ${ }^{15-17}$

In 2013 our hospital implemented an emergency response team for critically ill general medical patients in the ED, after several years with similar teams for trauma and cardiac arrest patients. In order to contribute to the knowledgebase about team management of these patients in the ED setting, we aimed to investigate the use of team versus standard care for this patient group. The objective was to investigate how management by team was associated with ED quality of care, ED resource use and patient outcome compared with standard care.

\section{METHODS}

\section{Study setting}

This retrospective single-centre cohort study used register data in 2015 and 2016 from Oslo University Hospital (OUH) Ullevål, a tertiary hospital with all subspecialties in internal medicine. The ED is considered large-volume with 28000 patients in 2015 and an admittance rate of $90 \%$. Half of the admitted patients were adult medical patients. In Norway self-referral is rare. Patients are usually referred to the ED by primary care physicians or ambulance personnel by telephone before arrival. No emergency medicine specialty existed at the time of the study, and patients were reviewed in the ED by on-call specialists (in internal medicine, orthopaedic, neurology, etc) appropriate to their presenting complaint.

In addition to an emergency response team for critically ill medical patients, the ED also had teams for trauma patients, patients who had cardiac arrest, critically ill children, patients with ST-elevation myocardial infarction and patients who had a stroke considered for thrombolysis, the latter from 2016.

All team patients were categorised as triage 1 . All other patients were triaged according to the Manchester Triage System. Triage was an ongoing process, and all patients could be assigned a different triage category later in the ED stay than at arrival if their condition changed. This included alerting the relevant emergency response team if the criteria was present. No rapid response team existed in the hospital or in the ED.

\section{Participants and management}

Triage 1 and 2 patients referred to the medical specialties were considered to be potentially critically ill and eligible for inclusion. Triage 1 patients were mostly identified

\begin{tabular}{ll}
$\begin{array}{l}\text { Table } 1 \text { OUH criteria and members of the emergency } \\
\text { response team }\end{array}$ & Team members \\
\hline OUH criteria & $\begin{array}{l}\text { Registrar in internal medicine } \\
\text { (team leader) }\end{array}$ \\
\hline Threatened airway & Registrar in anaesthesiology \\
\hline $\begin{array}{l}\text { Respiratory arrest } \\
\text { Respiration rate }<8 \text { or }>40^{*}\end{array}$ & ED nurses (3) \\
\hline $\begin{array}{l}\text { Oxygen saturation }<85 \% * \\
\text { Systolic blood } \\
\text { pressure }<90 \text { mm Hg* }\end{array}$ & Phlebotomist \\
$\begin{array}{l}\text { Pulse }<35 \text { or }>130^{*} \\
\text { GCS }<9^{*}\end{array}$ & $\begin{array}{l}\text { Radiographer } \\
\text { If needed, supplemented by } \\
\text { Persistent/continuous fitting } \\
\text { in neurology or registrar in } \\
\text { Temperature }<32^{*}\end{array}$ \\
$\begin{array}{l}\text { Clinical concern by } \\
\text { prehospital personnel, ED } \\
\text { doctor or ED nurse }\end{array}$ & \\
\hline
\end{tabular}

*Vital sign criteria.

ED, emergency department; GCS, Glasgow Coma Scale; OUH, Oslo University Hospital.

prior to arrival or at ED triage by using a single-parameter criteria system, hereafter called the OUH criteria. They were managed in resuscitation rooms by a multidisciplinary team (table 1). The team was led by a registrar in internal medicine, and the patients were assessed and managed using an Airway, Breathing, Circulation, Disability, Environment/extra (ABCDE) approach. Triage 2 patients were seen immediately by an ED nurse and within $10 \mathrm{~min}$ by a registrar in internal medicine, and thus received what is defined as standard care in this study. If needed, care was supplemented by additional ED nurses and/or physicians.

To reduce heterogeneity in acuity between the two groups, we only included patients with National Early Warning Score 2 (NEWS2) 5-10 points, excluding those missing 3 or more NEWS2 part scores. A cut-off of $\geq 5$ was chosen due to its increased risk of serious clinical outcome and recommendation as a threshold for urgent clinical review by a clinician or team. ${ }^{18}$ A cut-off of $\leq 10$ was chosen due to few triage 2 patients with higher scores and to avoid outliers that obviously were critically ill. We excluded patients under 18 years and those with the orders 'Not for resuscitation' or 'Not for ICU' given in the ED (figure 1).

\section{Data sources and sample size}

Data on triage 1 patients were retrieved from a quality register containing data from medical records on all medical triage 1 patients from 2015 and 2016, except for 44 patients not holding a Norwegian social security number $(\mathrm{n}=1294)$. Data on triage 2 patients were retrieved from a quality register containing similar data on every fifth admitted medical triage 2 patient from the same time period $(n=1426)$. In the latter register every 


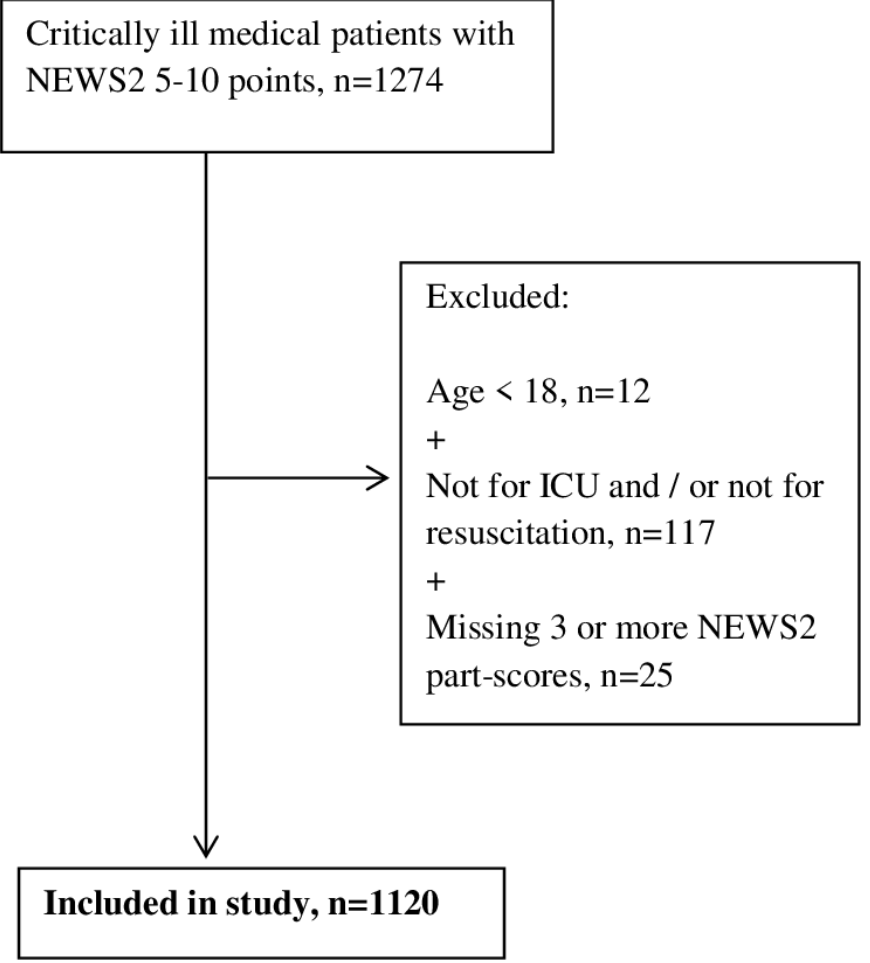

Figure 1 Flow chart of the included and excluded patients. ICU, intensive care unit; NEWS2, National Early Warning Score 2.

fifth arriving patient had been chosen in order to get a similar amount of patients as in the register for triage 1 patients and to get a spread in time of day, week and year.

Sample size was a pragmatic choice and not calculated, as inclusion was limited to eligible patients from the registers. By applying the rule of ten, ${ }^{19}$ the sample size was considered sufficient for the analyses chosen.

\section{Outcomes and variables}

Quality of care was investigated using four outcomes: pain assessment documented, ${ }^{20}$ analgesics given within $20 \mathrm{~min}^{21}{ }^{21}$ complete set of vital signs documented ${ }^{22}$ and antibiotics within $60 \mathrm{~min}$ if sepsis. ${ }^{23}$ Vital signs included respiration rate, oxygen saturation, pulse, blood pressure, temperature and Glasgow Coma Scale (GCS) ${ }^{22}$ Sepsis was defined as an infection being the main discharge diagnosis and $\geq 2$ quick Sepsis Related Organ Failure Assessment (qSOFA) or $\geq 2$ Systemic Inflammatory Response Syndrom (SIRS) criteria present on arrival, thus covering both current diagnostic criteria and those used in the study period. ${ }^{24}$

Resource use was investigated using three outcomes: $>3$ diagnostic interventions, critical care in the ED and ED LOS < $180 \mathrm{~min}$. Diagnostic intervention was defined as ECG, arterial blood gas, blood culture, other microbiological investigation, lumbar puncture, chest X-ray, other X-ray, CT of the head, other CT, cardiac ultrasound or other ultrasound. Critical care in the ED was defined as one or more of the following interventions or medications: intubation, other airway interventions, non-invasive ventilation, arterial line, central venous line, pacing, cardioversion, cardiopulmonary resuscitation, pleural catheter or administration of blood products, sedatives, anaesthetic agents, antiarrhythmics or vasopressors. ${ }^{25}$

Four outcomes were used to investigate patient outcome: ICU admission, ICU LOS <66 hours, hospital LOS < 194hours and mortality. ICU admission was defined as admission to any ICU in the hospital directly from the ED. Mortality was defined as mortality at 30 days or hospital mortality later than 30 days.

The cut-offs for ED, ICU and hospital LOS were made using the 75 th percentiles. All outcome variables were dichotomous.

In multivariate analysis, Charlson Comorbidity Index $(\mathrm{CCI})^{26}$ and history of substance abuse and/or psychiatric illness were used as comorbidity variables; the first was categorised as $0 p, 1-2 p, 3-4 p$ and $>4 p,{ }^{27}$ while the latter was dichotomous. The variable 'deranged vital signs' was defined as GCS $<15$ or NEWS2 $7-10$ or OUH criteria at arrival and was dichotomous.

Other variables included presenting complaint, which was grouped into categories based on frequency, and main discharge diagnosis, which was grouped accordingly.

\section{Statistical analysis}

Analyses were performed using IBM SPSS V.25.0 for Windows. Continuous variables are presented as median with IQR and categorical variables as number and percentage. Separate n's are reported for variables with missing items from the registers. Group comparison used Mann-Whitney rank-sum test for continuous variables and $\chi^{2}$ test or exact test for categorical variables and was two-sided.

Multivariate logistic regression was used to investigate the association with the outcomes, and clinical rationale was used to build the models (online supplemental file 1). For all outcomes we adjusted for gender, age, CCI, history of substance abuse and/or psychiatric history, and deranged vital signs. For complete set of vital signs, pain assessment documented, analgesics within $20 \mathrm{~min}$, antibiotics within $60 \mathrm{~min}$ if sepsis, $>3$ diagnostic interventions, ICU admission and ICU LOS $<66$ hours, we also adjusted for critical care in the ED. For the other outcomes, except critical care in the ED, we adjusted for critical care in the ED and/or ICU admission. For all outcomes we did sensitivity analyses, where also the presenting problem was adjusted for as this variable was considered to be also a potential confounder. Unadjusted and adjusted ORs with CIs, as well as p values, are presented. The goodness of fit was assessed using Hosmer-Lemeshow test.

A p value $<0.05$ was regarded as statistically significant in all analyses.

\section{Ethics}

All data were register data extracted from medical records, and treatment was not affected. Informed consent was therefore waived. 


\section{Patient and public involvement}

Patients or the public were not involved in any phase of this study.

\section{RESULTS}

\section{Patient characteristics}

A total of 1120 patients, of whom 691 (61.7\%) were managed by the team, met the inclusion criteria. The median age was 66 years, $599(53.5 \%)$ were male, and respiratory $(n=245,22.4 \%)$ and infection $(n=211,19.3 \%)$ problems were the most common presenting complaints (table 2). Patients managed by the team were younger $(\mathrm{p}<0.001)$, more were male $(\mathrm{p}<0.05)$, and had lower CCI but more history of substance abuse and/or psychiatric illness than those who received standard care (both $\mathrm{p}<0.001)$. More team patients also had OUH vital sign criteria present, NEWS2 7-10 points, decreased GCS and deranged vital signs $($ all $\mathrm{p}<0.001)$. Presenting complaint and discharge diagnoses differed between the two groups (both $\mathrm{p}<0.001$ ), with acute poisoning being dominant for team patients and infection being dominant for standard care patients.

\section{Quality of care}

Pain assessment was documented for 132 (11.8\%) patients, and for $720(64.3 \%)$ a complete set of vital signs were documented (table 3). Of the 291 (26.0\%) patients receiving analgesics, $69(24.3 \%)$ received it within $20 \mathrm{~min}$. Antibiotic treatment was started within $60 \mathrm{~min}$ to a total of $86(49.7 \%)$ patients with sepsis. In univariate analyses, significantly fewer team than standard care patients had pain assessment documented, but more had a complete set of vital signs documented (both $\mathrm{p}<0.001$ ) (table 3). More also received analgesics within $20 \mathrm{~min}$ and antibiotics within $60 \mathrm{~min}$ if sepsis, and the median time to analgesics and antibiotics was shorter (all $\mathrm{p}<0.001$ ).

In multivariate analyses, team management continued to be associated with having a complete set of vital signs documented (OR 1.720, CI 1.254 to 2.360), less documentation of pain assessment (OR 0.068, CI 0.037 to 0.128 ), and receive analgesics within $20 \mathrm{~min}$ (OR 3.268, CI 1.375 to 7.767 ) and antibiotics within $60 \mathrm{~min}$ if sepsis (OR 7.880, CI 3.322 to 18.691) (table 4). Sensitivity analyses adjusting also for presenting complaint did not alter the results (online supplemental file 2 ).

\section{Resource use}

Critical care was given to $525(46.9 \%)$ patients in the ED and $599(53.5 \%)$ had $>3$ diagnostic interventions (table 3). Significantly more team than standard care patients received critical care in the ED in univariate analyses, but fewer had $>3$ diagnostic interventions (both $\mathrm{p}<0.001$ ) (table 3 ). They had shorter median ED LOS than standard care patients, and more had ED LOS $<180$ min (both $\mathrm{p}<0.001$ ).

In multivariate analyses, management by team continued to be associated with receiving critical care in the ED (OR 9.900, CI 7.127 to 13.751) and an ED LOS $<180 \mathrm{~min}$ (OR 2.944, CI 2.070 to 4.187) (table 4). Sensitivity analyses adjusting also for presenting complaint did not alter the results (online supplemental file 2).

\section{Patient outcome}

A total of 496 (44.3\%) patients were admitted to ICU and $119(10.6 \%)$ were dead at 30 days or hospital discharge. Significantly more team than standard care patients were admitted to ICU in univariate analyses $(p<0.001)$ (table 3). They had shorter median ICU LOS $(\mathrm{p}<0.05)$ and hospital LOS $(\mathrm{p}<0.001)$ than standard care patients. There were no differences in ICU LOS $<66$ hours, hospital LOS $<194$ hours or mortality.

Management by team continued to be associated with ICU admission (OR 2.763, CI 1.962 to 3.891 ) in multivariate analyses. It was also associated with mortality (OR 1.882, CI 1.142 to 3.102) (table 4). No association was found with ICU LOS $<67$ hours or hospital LOS $<194$ hours. Sensitivity analyses adjusting also for presenting complaint did not alter the results (online supplemental file 2).

\section{DISCUSSION}

For quality of care, management by team was associated with complete set of vital signs documented and administration of analgesics within $20 \mathrm{~min}$ and antibiotics within $60 \mathrm{~min}$ if sepsis. It was negatively associated with documentation of pain assessment. For resource use, management by team was associated with receiving critical care in the ED and an ED LOS $<180$ min. For patient outcome, association was found with ICU admission and mortality. No association was found with ICU LOS $<66$ hours or hospital LOS $<194$ hours.

\section{Quality of care}

The investigation of quality of care in EDs often focuses on process indicators. Suggested indicators include time intervals such as LOS, time to ED provider, time to analgesics, time to investigations and time to decisions and treatment. $^{20} 2829$ Also the percentage of patients with documented pain assessment is suggested, ${ }^{20}$ as is having a full set of vital signs documented.22

We found few studies comparing the effect of management by team on these processes for critically ill medical patients. One recent practice improvement study found that introduction of a team response to critically ill medical patients reduced the time of several ED processes, namely time to provider, laboratory, diagnostic imaging and admission. ${ }^{17}$ We found that administration of analgesics within $20 \mathrm{~min}$ and antibiotics within $60 \mathrm{~min}$ if sepsis had better outcome by use of team compared with standard care. For patients with sepsis a recent review found that management by a team improved sepsis resuscitation bundle, in which administration of antibiotics within $60 \mathrm{~min}$ is a major component. ${ }^{10}$ This is consistent with our findings. Management by team is found to have a 
Table 2 Patients' characteristics

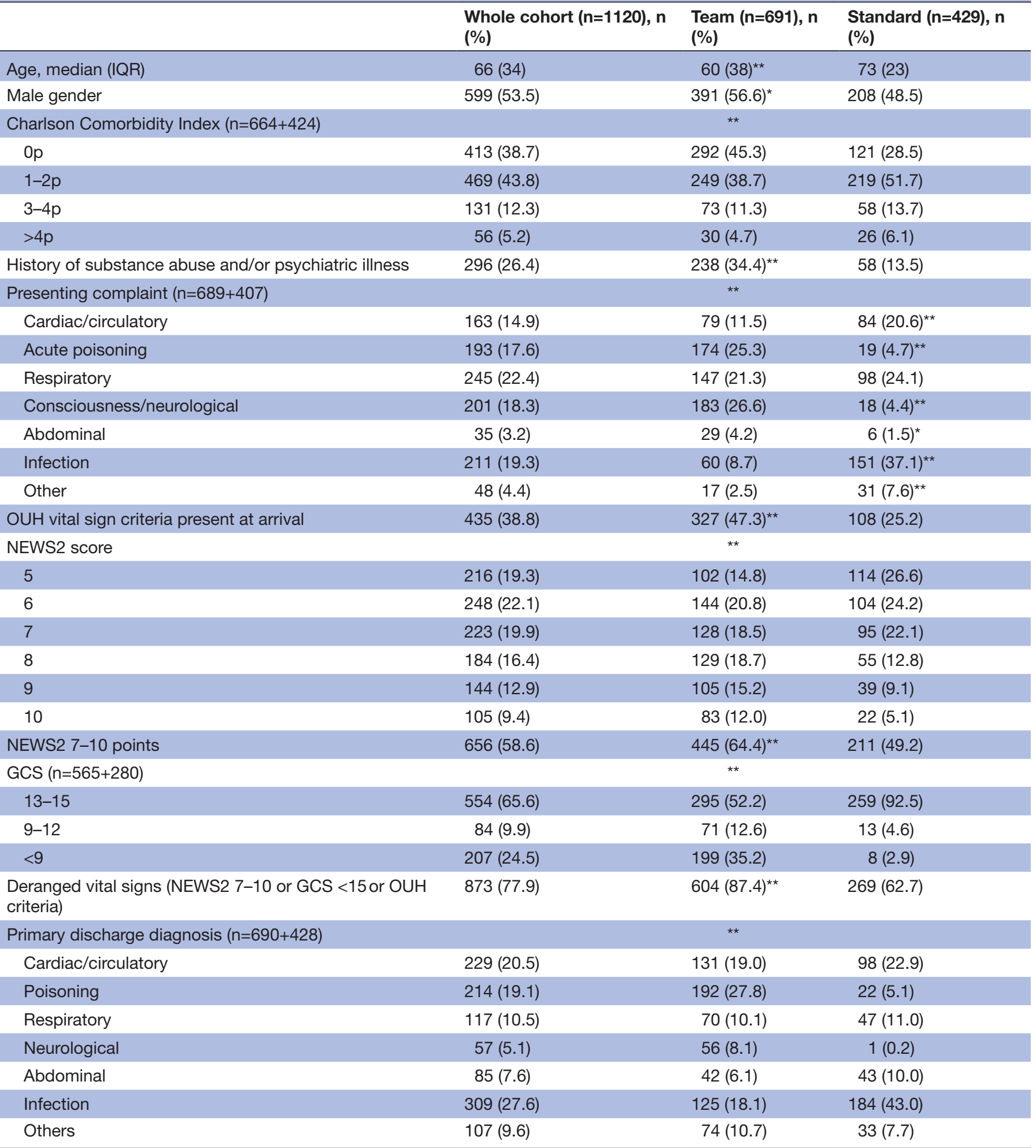

${ }^{*} \mathrm{P}<0.05,{ }^{* *} \mathrm{P}<0.001$.

GCS, Glasgow Coma Scale; ; NEWS2, National Early Warning Score 2; OUH, Oslo University Hospital.

positive effect on door-to-needle time in patients who had a stroke and myocardial infarction, ${ }^{78}$ further supporting that team management is beneficial in reducing timecritical treatment.
Team management also had a positive association with documentation of a complete set of vital signs, which other studies have found to be incomplete in many ED patients. ${ }^{30-32}$ Less documentation of vital signs at arrival 
Table 3 Quality of care, resource use and patient outcome: univariate analysis

\begin{tabular}{|c|c|c|c|}
\hline & Whole cohort ( $n=1120), n(\%)$ & Team (n=691), n (\%) & $\begin{array}{l}\text { Standard }(n=429) \text {, } \\
n(\%)\end{array}$ \\
\hline \multicolumn{4}{|l|}{ Quality of care } \\
\hline Pain assessment documented & $132(11.8)$ & $15(2.2)^{\star \star}$ & $117(27.3)$ \\
\hline Complete set of vital signs documented & $720(64.3)$ & $474(68.6)^{\star *}$ & $246(57.3)$ \\
\hline Analgesics given & $291(26.0)$ & $188(27.2)$ & $103(24.0)$ \\
\hline Minutes to analgesics, median (IQR) $(n=184+100)$ & $43(53.5)$ & $32(66)^{\star \star}$ & $63(66)$ \\
\hline Analgesics within $20 \min (n=184+100)$ & $69(24.3)$ & $57(31.0)^{\star \star}$ & $12(12.0)$ \\
\hline Sepsis (infection $+\geq 2$ qSOFA or $\geq 2$ SIRS) & $268(23.9)$ & $113(16.4)^{\star \star}$ & $155(36.1)$ \\
\hline Antibiotics given $(n=113+155)$ & $179(66.8)$ & $75(66.4)$ & $104(67.1)$ \\
\hline Minutes to antibiotics, median (IQR) $(n=74+99)$ & $60(81)$ & $30.5(31.8)^{\star *}$ & $94(75)$ \\
\hline Antibiotics within $60 \min (n=74+99)$ & $86(49.7)$ & $59(79.7)^{\star \star}$ & $27(27.3)$ \\
\hline \multicolumn{4}{|l|}{ Resource use } \\
\hline Diagnostic interventions & & ** & \\
\hline 0 & $8(0.7)$ & $7(1.0)$ & $1(0.2)$ \\
\hline 1 & $78(7.0)$ & $47(6.8)$ & $31(7.2)$ \\
\hline 2 & $161(14.4)$ & $115(16.6)$ & $46(10.7)$ \\
\hline 3 & $274(24.5)$ & $197(28.5)$ & $77(17.9)$ \\
\hline 4 & $276(24.6)$ & $167(24.2)$ & $109(25.4)$ \\
\hline 5 & $253(22.6)$ & $120(17.4)$ & $133(31.0)$ \\
\hline$>5$ & $70(6.3)$ & $38(5.5)$ & $32(7.5)$ \\
\hline$>3$ diagnostic interventions & $599(53.5)$ & $325(47.0)^{\star \star}$ & 247 (63.9) \\
\hline Critical care in the ED, any & $525(46.9)$ & $461(66.7)^{\star \star}$ & $64(14.9)$ \\
\hline Interventions & $411(36.7)$ & $390(56.4)^{\star \star}$ & $21(4.9)$ \\
\hline Medications & $294(26.3)$ & $244(35.3)^{\star \star}$ & $50(11.7)$ \\
\hline Critical care in the ED and/or ICU admission & $663(59.2)$ & $551(79.7)^{\star \star}$ & $112(26.1)$ \\
\hline \multicolumn{4}{|l|}{ ED LOS } \\
\hline Median min (IQR) & $116(109)$ & $91(78)^{\star \star}$ & $161(111)$ \\
\hline$<180 \min$ & $840(75.0)$ & $586(84.8)^{* *}$ & $254(59.2)$ \\
\hline \multicolumn{4}{|l|}{ Patient outcome } \\
\hline ICU admission & $496(44.3)$ & $416(60.2)^{\star \star}$ & $80(18.6)$ \\
\hline \multicolumn{4}{|l|}{ ICU LOS } \\
\hline Median hours (IQR) $(n=416+80)$ & $27.5(52)$ & $25.5(50)^{*}$ & $42.5(68)$ \\
\hline$<66$ hours $(n=416+80)$ & $369(74.4)$ & $316(76.0)$ & $53(66.3)$ \\
\hline \multicolumn{4}{|l|}{ Hospital LOS } \\
\hline Median hours (IQR) & 96 (169) & $67(174)^{\star \star}$ & $125(143)$ \\
\hline$<194$ hours & $838(74.8)$ & $525(76.0)$ & $313(73.0)$ \\
\hline Mortality at 30 days/hospital discharge & $119(10.6)$ & $79(11.4)$ & $40(9.3)$ \\
\hline
\end{tabular}

${ }^{\star} \mathrm{P}<0.05,{ }^{\star *} \mathrm{P}<0.001$.

ED, emergency department; ICU, intensive care unit; LOS, length of stay; qSOFA, quick Sepsis Related Organ Failure Assessment; SIRS, Systematic Inflammatory Response Syndrome.

in the standard care group is surprising, as local guidelines mandate vital signs to be documented at triage and throughout the ED stay. An Australian study found that the vital sign most commonly missing in ED documentation was GCS, ${ }^{30}$ which in our study is missing more frequently for standard care than team patients. A reason for this could be that nurses tend to omit documentation of GCS when the patient is awake and alert, while it is considered more important to document if decreased. GCS is also more complex to measure than the other vital signs. This could potentially cause nurses to avoid measuring it, unlike a team with more competence in GCS measurement. 
Table 4 Multivariate analyses of team management versus standard care $(n=1068$ unless otherwise stated)

\begin{tabular}{|c|c|c|}
\hline Outcomes & Crude OR (Cl) & Adjusted OR (Cl)† \\
\hline \multicolumn{3}{|l|}{ Quality of care } \\
\hline Complete set of vital signs documented $\ddagger$ & $1.625(1.266 \text { to } 2.086)^{\star \star}$ & $1.720(1.254 \text { to } 2.360)^{\star}$ \\
\hline Pain assessment documented $\ddagger$ & $0.059(0.034 \text { to } 0.103)^{\star *}$ & $0.068(0.037 \text { to } 0.128)^{\star *}$ \\
\hline Analgesics within $20 \min \ddagger(n=272)$ & $3.291(1.669 \text { to } 6.492)^{*}$ & $3.268(1.375 \text { to } 7.767)^{\star}$ \\
\hline Antibiotics within 60 min if sepsis $¥(n=170)$ & $10.489(5.111 \text { to } 21.525)^{\star \star}$ & $7.880(3.322 \text { to } 18.691)^{\star \star}$ \\
\hline \multicolumn{3}{|l|}{ Resource use } \\
\hline >3 diagnostic interventions $\ddagger$ & $0.502(0.392 \text { to } 0.643)^{\star *}$ & $0.749(0.545$ to 1.030$)$ \\
\hline Critical care in the ED & $11.431(8.391 \text { to } 15.572)^{\star \star}$ & $9.900(7.127 \text { to } 13.751)^{\star \star}$ \\
\hline ED LOS $<180 \mathrm{~min} \S$ & $3.845(2.897 \text { to } 5.104)^{\star *}$ & $2.944(2.070 \text { to } 4.187)^{\star \star}$ \\
\hline \multicolumn{3}{|l|}{ Patient outcome } \\
\hline ICU admission $\neq$ & $6.599(4.954 \text { to } 8.791)^{\star *}$ & $2.763(1.962 \text { to } 3.891)^{\star \star}$ \\
\hline ICU LOS <66 hours $\ddagger(n=464)$ & 1.610 (0.962 to 2.695$)$ & $1.374(0.764$ to 2.472$)$ \\
\hline Hospital LOS <194 hours§ & $1.172(0.890$ to 1.544$)$ & $1.194(0.837$ to 1.703$)$ \\
\hline Mortality§ & $1.255(0.841$ to 1.875$)$ & $1.882(1.142 \text { to } 3.102)^{\star}$ \\
\hline
\end{tabular}

${ }^{*} \mathrm{P}<0.05,{ }^{* *} \mathrm{P}<0.001$.

†All adjusted for age, gender, Charlson comorbidity score, substance abuse or psychiatric history, and deranged vital signs.

$\ddagger$ Adjusted for critical care in the ED.

$\S$ Adjusted for critical care in the ED and/or ICU admission.

ED, emergency department; ICU, intensive care unit; ; LOS, length of stay.

Documentation of pain assessment was poorer for team patients than standard care patients. We adjusted for deranged vital signs, which included patients with decreased consciousness, one factor that could influence this documentation. The better result for standard care patients could be due to the triage process, in which pain assessment is integrated. ${ }^{33}$ It could also be that teams responding to alerts of critical patients focus on life-saving interventions, at the expense of pain assessment. Another explanation could be that in patients who clearly are in pain, the pain is managed without first documenting pain assessment. This is supported by the finding that more team patients received analgesics within $20 \mathrm{~min}$. We nevertheless argue that documentation of pain assessment should be an integrated part of any assessment of conscious patients, and a team should have the resources to do this alongside other interventions.

In a general patient population of critically ill as this, different diagnoses will require different treatment, of which only a few will be time-critical in the same way as for the abovementioned patient groups. There is a need to develop quality indicators specific for critically ill general medical patients in the future.

\section{Resource use}

The odds of receiving critical care in the ED were more than nine for the team patients compared with standard care patients, despite adjusting for several factors including deranged vital signs. The presence of team members with critical care competencies could be a reason for this, as they most likely are better at identifying patients who need these interventions and have the skills to perform them. It could also be that when a team alert is used, the anticipation of team members is that the patient truly is critically ill. This could cause initiation of critical care interventions like arterial line insertion, also when this might not be necessary. It is also possible that an unknown factor, such as severity of the illness, not covered by adjusting factors, was present in the team patients.

The shorter ED LOS when patients were managed by team is in line with other studies. ${ }^{13} 17$ Prolonged ED LOS is thought to impact on quality of initial care, and can thus cause prolonged ventilator time in the ICU and even increase mortality. ${ }^{12}$ It seems logical that a multidisciplinary team with more people and better critical care competencies manages patients quicker and with higher quality than standard care management. We also believe that in our setting the reduced ED LOS is caused by the team leader being a medical registrar with easy access to medical ICU beds.

\section{Patient outcome}

The odds of ICU admission were higher for patients managed by team compared with those receiving standard care, despite adjusting for factors that could impact on ICU admission, such as deranged vital signs and receiving critical care in the ED. This could be due to factors already discussed; the competencies of the team to identify patients in need of ICU admission could be better than of those giving standard care. It could also be due to the team management itself, an anticipation that the patient is critically ill due to the team alert, as well as 
easy access to ICU beds and willingness to increase level of care for team patients.

Management by team was also associated with increased odds of mortality. The mortality variable was a combination of mortality during hospital stay and 30-day mortality, and thus an outcome quite far away in time from initial management in the ED. The use of outcomes far away in time from the ED stay when investigating ED management has been criticised, as factors after the ED stay may influence outcome. ${ }^{34}$ It could also be that the team patients were sicker than the standard care patients, and that a factor not controlled for by adjusting for deranged vital signs was present. An unknown factor such as poor prognosis of condition, on which we had no data, could influence mortality.

The other factors far away in time from the ED stay, ICU LOS and hospital LOS were not affected by team management in the multivariate analyses, despite the median LOS being shorter in univariate analysis. We believe the reasons could be similar to those discussed for mortality.

\section{Limitations}

This study collected data from two quality registers with data from medical records. The registers contained data mainly about ED management and few data from the post-ED period. This limited the analyses of long-term outcomes such as mortality, ICU LOS and hospital LOS. Influencing factors such as complications, adverse events or decisions regarding limitation of treatment after the ED stay could not be adjusted for. This limitation in data does however mimic real life in ED management. It should be emphasised that ED management should be the best considering available data at the moment. As such, data on ED processes could be more interesting than long-term outcomes on which several later factors may be influential. We have also previously suggested that later outcomes may be less relevant than outcomes close to the ED stay, and have recommended use of 24-hour or 48-hour mortality, ${ }^{35}$ if available.

The use of register data also limited the amount of quality indicators that could be investigated. One interesting indicator would have been patient satisfaction; this was not present in the registers. This could be difficult to investigate also with other methods due to the critical illness of the patients. Using data from registers reduced selection bias and contributed to a high inclusion rate, as all triage 1 and every fifth triage 2 patients were included in the registers.

The observational nature of the study makes it difficult to draw conclusions about the cause and effect of the two types of management under investigation. The use of multivariate analysis made it possible to investigate the associations, which enhance the knowledgebase for the management of this patient group and could be a starting point for future research. The study was also from a single ED and may not be representative of other EDs.

We included patients with one or two missing NEWS2 part scores. The presence of the missing scores could have resulted in a NEWS2 higher than 10 points, the upper limit for inclusion. More triage 2 than triage 1 patients had missing NEWS2 part scores, and thus potentially higher NEWS2, so we do not believe inclusion of patients with missing part scores has impacted on the results.

\section{Considerations for future research and practice}

We recommend prospective interventional studies in the future, preferably multisite and international, to gain more knowledge about the best ED management of this, in our opinion, often downgraded patient group.

In addition, cost-analysis studies would give knowledge of other aspects of resource use than in the present study, and could inform ED and hospital managers on how to manage this patient group in a way that is high in quality without overusing resources.

Future observational research should include potential confounding variables from the post-ED period if investigating late outcomes. It should also include data concerning the prognosis of patients' conditions, also a potential confounding factor.

Our findings support findings from previous studies of similar or comparable patient groups, suggesting that emergency response team improves quality of care and processes in the ED for critically ill medical patients. We therefore recommend implementation of such teams in more EDs, preferably in conjunction with studies evaluating the effect.

\section{CONCLUSION}

We found that management by a multidisciplinary emergency response team had a positive association with several outcomes for quality of care, implying that quality is improved when critically ill medical patients are managed by a team compared with receiving standard care. Outcomes for resource use were ambiguous; team management was associated with shorter ED LOS, but more critical care. For patient outcomes after the initial ED treatment, the results were divergent; team management had no association with ICU LOS and hospital LOS, but was associated with increased mortality. It was also associated with ICU admission, an outcome closer in time.

As a starting point this observational study found promising results on managing critically ill medical patients with an emergency team rather than standard care. Further studies, preferably of prospective and interventional nature, should be performed to investigate the optimal and most cost-effective management of this patient group in the future.

\section{Author affiliations}

${ }^{1}$ Emergency Department, Division of Emergencies and Critical Care, Oslo University Hospital, Oslo, Norway

${ }^{2}$ Institute of Clinical Medicine, University of Oslo, Oslo, Norway

${ }^{3}$ Department of Forensic Sciences, Oslo University Hospital, Oslo, Norway

${ }^{4}$ Institute of Health and Society, University of Oslo, Oslo, Norway 
${ }^{5}$ Department of Acute Medicine, Division of Medicine, Oslo University Hospital, Oslo, Norway

${ }^{6}$ Joint Medical Services, Norwegian Armed Forces, Sessvollmoen, Norway ${ }^{7}$ Department of Corporate Governance, South-Eastern Norway Regional Health Authority, Hamar, Norway

Acknowledgements The authors wish to thank Inger Larsen for support in preparing and executing the study and all staff involved in treating the patients and collecting the data. We also thank Kjetil Røysland for statistical advice.

Contributors SE: conceptualisation, methodology, formal analysis, writingoriginal draft. DJ, STB: conceptualisation, methodology, writing-review and editing, supervision. RR: conceptualisation, methodology, writing-review and editing, supervision, project administration.

Funding The authors have not declared a specific grant for this research from any funding agency in the public, commercial or not-for-profit sectors.

Competing interests None declared.

Patient consent for publication Not required.

Ethics approval The study was approved by the Data Protection Officer at OUH (2016/10319)

\section{Provenance and peer review Not commissioned; externally peer reviewed.}

Data availability statement № data are available. The dataset analysed during the current study are not publicly available due to restrictions from the Data Protection Officer at Oslo University Hospital.

Supplemental material This content has been supplied by the author(s). It has not been vetted by BMJ Publishing Group Limited (BMJ) and may not have been peer-reviewed. Any opinions or recommendations discussed are solely those of the author(s) and are not endorsed by BMJ. BMJ disclaims all liability and responsibility arising from any reliance placed on the content. Where the content includes any translated material, BMJ does not warrant the accuracy and reliability of the translations (including but not limited to local regulations, clinical guidelines, terminology, drug names and drug dosages), and is not responsible for any error and/or omissions arising from translation and adaptation or otherwise.

Open access This is an open access article distributed in accordance with the Creative Commons Attribution Non Commercial (CC BY-NC 4.0) license, which permits others to distribute, remix, adapt, build upon this work non-commercially, and license their derivative works on different terms, provided the original work is properly cited, appropriate credit is given, any changes made indicated, and the use is non-commercial. See: http://creativecommons.org/licenses/by-nc/4.0/.

ORCID iD

Stine Engebretsen http://orcid.org/0000-0002-9951-4145

\section{REFERENCES}

1 American College of Surgeons. Resources for optimal care of the injured patient.6th. Chicago: American College of Surgeons, 2014.

2 Soar J, Nolan JP, Böttiger BW, et al. European resuscitation Council guidelines for resuscitation 2015: section 3. adult advanced life support. Resuscitation 2015;95:100-47.

3 Powers WJ, Rabinstein AA, Ackerson T, et al. 2018 guidelines for the early management of patients with acute ischemic stroke: a guideline for healthcare professionals from the American heart Association/ American stroke association. Stroke 2018;49:e46-110.

4 O'Gara PT, Kushner FG, Ascheim DD, et al. 2013 ACCF/AHA guideline for the management of ST-elevation myocardial infarction: a report of the American College of cardiology Foundation/American heart association Task force on practice guidelines. J Am Coll Cardiol 2013;61:e78-140.

5 McNeill G, Bryden D. Do either early warning systems or emergency response teams improve hospital patient survival? A systematic review. Resuscitation 2013;84:1652-67.

6 Harris T, Davenport R, Hurst T, et al. Improving outcome in severe trauma: trauma systems and initial management: intubation, ventilation and resuscitation. Postgrad Med J 2012;88:588-94.

7 Nazir FS, Petre I, Dewey HM. Introduction of an acute stroke team: an effective approach to hasten assessment and management of stroke in the emergency department. J Clin Neurosci 2009;16:21-5.

8 Camp-Rogers T, Dante S, Kontos MC, et al. The impact of prehospital activation of the cardiac catheterization team on time to treatment for patients presenting with ST-segment-elevation myocardial infarction. Am J Emerg Med 2011;29:1117-24.

9 Hamidon BB, Dewey HM. Impact of acute stroke team emergency calls on in-hospital delays in acute stroke care. J Clin Neurosci 2007;14:831-4.

10 Bloos F. The importance of a hospital-dedicated sepsis response team. Expert Rev Anti Infect Ther 2020;18:1235-43.

11 Stevens JP. Rapid Response systems. Up to Date, 2020. Available: https://www.uptodate.com/contents/rapid-response-systems [Accessed 14 Oct 2020].

12 McDowald K, Direktor S, Hynes EA, et al. Effectiveness of collaboration between emergency department and intensive care unit teams on mortality rates of patients presenting with critical illness: a systematic review. JBI Database System Rev Implement Rep 2017:15:2365-89.

13 Durie ML, Darvall JN, Hadley DA, et al. A "Code ICU" expedited review of critically ill patients is associated with reduced emergency department length of stay and duration of mechanical ventilation. $J$ Crit Care 2017;42:123-8.

14 Mathews KS, Durst MS, Vargas-Torres C, et al. Effect of emergency department and ICU occupancy on admission decisions and outcomes for critically ill patients. Crit Care Med 2018;46:720-7.

15 Lafrenz T, Lindberg Søren Østergaard, La Cour JL, et al. Emergency teams in Danish emergency departments. Dan Med J 2012;59:A4451.

16 Christensen D, Maaløe R, Jensen NM, et al. Quality of care using a multidisciplinary team in the emergency room. Dan Med Bull 2011;58:A4227.

17 Perry A. Code critical: improving care delivery for critically ill patients in the emergency department. J Emerg Nurs 2020;46:199-204.

18 Royal College of Physicians. National early warning score (news) 2: standardising the assessment of acute-illness severity in the NHS updated report of a working Party. London: RCP, 2017.

19 Veierød MB, Lydersen S, Laake P. Medical statistics: in clinical and epidemiological research. Oslo: Gyldendal akademisk, 2012.

20 Schull MJ, Guttmann A, Leaver CA, et al. Prioritizing performance measurement for emergency department care: consensus on evidence-based quality of care indicators. CJEM 2011;13:300-9.

21 The College of Emergency Medicine. Management of pain in adults. best practice guideline. London: The College of Emergency Medicine, 2014.

22 The Royal College of Emergency Medicine. Vital signs in adults. National quality improvement project. National report 2018/19. The Royal College of Emergency Medicine, 2019.

23 Surviving sepsis campaign. Available: https://www.sccm.org/Survivin gSepsisCampaign/Home [Accessed 26 Aug 2020].

24 Singer M, Deutschman CS, Seymour CW, et al. The third International consensus definitions for sepsis and septic shock (Sepsis-3). JAMA 2016;315:801-10

25 Flabouris A, Chen J, Hillman K, et al. Timing and interventions of emergency teams during the merit study. Resuscitation 2010;81:25-30.

26 Charlson ME, Pompei P, Ales KL, et al. A new method of classifying prognostic comorbidity in longitudinal studies: development and validation. J Chronic Dis 1987;40:373-83.

27 Huang Y-qun, Gou R, Diao Y-shu, et al. Charlson comorbidity index helps predict the risk of mortality for patients with type 2 diabetic nephropathy. J Zhejiang Univ Sci B 2014;15:58-66.

28 Wiler JL, Welch S, Pines J, et al. Emergency department performance measures updates: proceedings of the 2014 emergency department benchmarking alliance consensus summit. Acad Emerg Med 2015;22:542-53.

29 Madsen M, Kiuru S, Castrèn M, et al. The level of evidence for emergency department performance indicators: systematic review. Eur J Emerg Med 2015;22:298-305

30 Considine J, Trotter C, Currey J. Nurses' documentation of physiological observations in three acute care settings. J Clin Nurs $2016 ;$;25:134-43. 01.

31 Johnson KD, Winkelman C, Burant CJ, et al. The factors that affect the frequency of vital sign monitoring in the emergency department. $J$ Emerg Nurs 2014;40:27-35.

32 Lambe K, Currey J, Considine J. Frequency of vital sign assessment and clinical deterioration in an Australian emergency department. Australas Emerg Nurs J $2016 ; ; 19: 217-22.01$.

33 Mackway-Jone K, Masden J, Windle J. Emergency triage: Manchester triage group. 3 ed. Chichester: John Wiley \& Sons, 2014

34 Twomey M, Wallis LA, Myers JE. Limitations in validating emergency department triage scales. Emerg Med J 2007;24:477-9.

35 Engebretsen S, Bogstrand ST, Jacobsen D, et al. NEWS2 versus a single-parameter system to identify critically ill medical patients in the emergency department. Resusc Plus 2020;3:100020. 